RU Построение индивидуальной траектории обучения студентов иностранному языку в интересах устойчивого развития образовательной системы

\author{
Васьбиева Д. Г.
}

\begin{abstract}
Аннотация. Цель исследования - построение индивидуальной траектории обучения студентов иностранному языку в неязыковом вузе. В статье рассмотрена актуальность построения данной траектории, обусловленная трансформацией образовательных программ в онлайн-платформы и происходящими событиями в экономике в условиях пандемии коронавируса. Научная новизна работы выражена в проектировании индивидуальной траектории обучения студентов иностранному языку, сочетающей в себе педагогический дизайн и анализ данных. В результате предложена модель индивидуальной траектории обучения студентов иностранному языку, использующая практические инструменты для создания инновационной образовательной среды с целью повышения мотивации и стремления студентов к учебе.
\end{abstract}

\title{
EN Developing Individual Path of Teaching a Foreign Language to Ensure Sustainable Development of Educational System
}

\begin{abstract}
Vasbieva D. G.
Abstract. The paper aims to develop an individual trajectory of teaching a foreign language to nonlinguistic students. According to the author, relevance of this trajectory is conditioned by digitalization of learning environments and by the current economic situation in the context of the coronavirus pandemic. Scientific originality of the study lies in the fact that relying on pedagogical design methods and the data analysis method, the researcher constructs an individual trajectory of teaching a foreign language. The research findings are as follows: the author suggests an individual trajectory of teaching a foreign language, which promotes formation of innovative educational environment, increases students' motivation for learning.
\end{abstract}

\section{Введение}

Актуальность нашего исследования продиктована особым интересом к построению индивидуальной траектории обучения студентов иностранному языку (ИЯ) в неязыковом вузе для устойчивого развития современной образовательной системы. Необходимость индивидуализации обучения обусловлена трансформацией образовательных программ в интерактивные онлайн-платформы и происходящими событиями в экономике в условиях пандемии коронавируса.

В последнее время большинство аспектов жизнедеятельности человека были перенесены в виртуальное пространство не только из-за широкого распространения информационных технологий, но также изза смертельно опасного коронавируса COVID-19. Во многих странах мира были предприняты меры для борьбы и сдерживания вспышки пандемии коронавируса, включающие частичную или полную изоляцию, закрытие образовательных учреждений: школ, колледжей и университетов. Таким образом, онлайн-обучение стало подавляющим ответом на эти закрытия. Другими словами, онлайн-обучение стало одним из способов борьбы с распространением инфекционного вируса, такого как COVID-19 [16]. Большинство руководителей университетов сейчас продвигают онлайн-образование как решение этого кризиса (ЮНЕСКО, 2020) [14; 18]. Более того, за последнее десятилетие наблюдается тенденция отказа от очного обучения и постепенного перевода образовательных программ в онлайн-платформы многими ведущими университетами мира (Оксфордский университет, Кембриджский университет, Пекинский университет, Гарвардский университет, Массачусетский технологический институт, Йельский университет и другие) [13; 17]. 
В образовании приоритетные направления подвергаются реорганизации, поскольку в условиях переизбытка научной информации требуется подготовить специалиста новой формации, способного применять творческий подход к овладению знаниями, умеющего адекватно, оперативно и критически реагировать на происходящие перемены и прогнозировать дальнейшее развитие событий. В связи с этим важное место в образовательной деятельности занимают разработка электронных обучающих платформ, актуализация содержания образования, приведение его в соответствие с современными требованиями, сложившейся ситуацией, такой как, например, пандемия, и перспективами развития общества. Следует отметить, что методологической основой современного образования может служить компетентностный подход, который нацелен на пересмотр существующих приоритетов и усиление практической ориентации образования для подготовки эрудированного и мобильного специалиста, владеющего необходимой системой знаний, а также технологиями и способами их получения. А умения будущего выпускника вуза ставить перед собой цель, анализировать ситуацию, планировать, эффективно действовать, проводить анализ результатов и самооценку будут определять деятельностные характеристики содержания образования.

С дидактических позиций методически грамотное использование электронных образовательных ресурсов будет «способствовать повышению результативности учебного процесса путем создания условий для реализации основных приоритетных направлений высшего образования, таких как компетентностный подход, непрерывное образование, переход к целям и содержанию образования, индивидуализация обучения и развитие самостоятельности обучающихся» [3, с. 251]. На наш взгляд, проблема персонификации и дифференциации обучения в аспекте проектирования индивидуальных образовательных траекторий остается значимой в учебно-познавательном процессе.

В соответствии с поставленной целью в данной научной статье решаются следующие задачи:

1) определение роли индивидуальной образовательной траектории в реализации личностного потенциала студента в образовании;

2) обзор теоретических подходов ученых к определению сущности понятия «индивидуальная образовательная траектория»;

3) анализ предложенной автором модели индивидуальной траектории обучения студентов ИЯ на основе данных образовательной деятельности.

В статье применяются следующие методы исследования: методы качественного анализа, обобщения и проектирования.

Теоретической базой исследования послужили труды по педагогике общего образования, высшей школы и психологии А. В. Хуторского [12], Э. Ф. Зеер, Э. Э. Сыманюк [5], П. В. Сысоева [10], А. М. Евсеевой [3], посвященные вопросам построения индивидуальной образовательной траектории. Кроме того, учитывались работы по проблемам дистанционного образования и индивидуализации обучения: А. А. Степаненко, А. В. Фещенко [9], В. Бао [13], Е. М. Муленга, Дж. М. Марбан [16], А. Г. Пиччиано [17].

Практическая значимость исследования заключается в том, что разработанная в статье модель, сочетающая в себе педагогический дизайн и анализ данных, может быть использована в процессе преподавания дисциплины «Иностранный язык» в вузе в интересах устойчивого развития образовательной системы. Важную роль в этой модели отводится дата-инжинирингу, отвечающему за сбор данных (цифровые следы) об учебном опыте и позволяющему:

- проводить анализ развития студента;

- выстраивать, корректировать индивидуальную образовательную траекторию на основе персонализации и кастомизации учебных планов (основанных на взаимодействии с работодателями) и применения искусственного интеллекта для формирования программ;

- создать инновационную образовательную среду.

Роль индивидуальной образовательной траектории в реализации личностного потенциала студента в образовании

В современных условиях индивидуальная образовательная траектория играет важнейшую роль в качестве персонального пути каждого обучающегося в реализации своего личностного потенциала в процессе обучения. Справедливо отметить, что под личностным потенциалом подразумевается совокупность познавательных, организационных, творческих, деятельностных и других способностей, которые могут быть выявлены и развиваться в процессе движения обучающегося по индивидуальной образовательной траектории.

Будучи многоаспектным процессом, индивидуальная образовательная траектория способна привить студентам самостоятельность и инициативность, обеспечить максимальную реализацию их познавательного и личностного потенциала в процессе обучения иностранному языку. Формирование способности сделать выбор, надлежащая готовность к профессиональному и жизненному самоопределению предоставляют будущему выпускнику вуза возможность реализовать себя в современных условиях, где успешность это результат хорошей вузовской подготовки с ориентацией на будущую профессию. В связи с этим перед российским высшим образованием стоит вызов - создать условия для формирования у студентов в процессе обучения способности к выбору целей, самообразованию и принятию решений, касающихся их будущей профессиональной деятельности. 


\section{Обзор теоретических подходов ученых}

\section{к определению сущности понятия «индивидуальная образовательная траектория»}

Вопросами построения индивидуальной образовательной траектории начали заниматься еще в конце XX начале XXI века, когда в отечественное образование вошло понятие «личностно ориентированное обучение». А. В. Хуторской предложил три подхода к личностно ориентированному обучению и сделал важный акцент на том, что «методологическим вектором проектирования и реализации образования выбран подход: от ученика, а не к нему. Исходной основой определения целей и траектории обучения выступает сам ученик, чья деятельность организуется с помощью педагога» [12]. Э. Ф. Зеер и Э. Э. Сыманюк в своем исследовании выделили внешние и внутренние факторы построения индивидуальных образовательных траекторий: «...внешние - миссия образовательной организации, ее институционная структура, социально-экономические потребности региона, квалификация педагогических работников; внутренние - целевые ориентации обучающихся, мотивы повышения образовательного уровня, познавательная активность, потребность в саморазвитии, самоотношение и направленность на будущее (транспективу)» [5, с. 77].

Итак, необходимость поиска новых более эффективных средств качественной подготовки выпускников вузов явилась предпосылкой повышенного интереса отечественных и зарубежных ученых к данной проблематике применительно к ИЯ. Обзор современной научно-методической литературы продемонстрировал многогранный характер проблемы, что послужило причиной существования различных толкований данной терминологии. Помимо этого, выделяется и разнообразие понятийного аппарата: «индивидуальная траектория обучения», «индивидуальная образовательная траектория», «индивидуальная траектория развития», «индивидуальная образовательная программа», «индивидуальный образовательный маршрут» и т.д.

Большинство ученых определяют индивидуальную образовательную траекторию как адресно смоделированную дифференцированную образовательную программу, которая предоставляет студенту возможность выбора предмета, затем разрабатывается и включается в образовательные программы, которые впоследствии реализуются преподавателями для раскрытия способностей и развития самостоятельности в обучении у студентов [15]. «Индивидуальный образовательный маршрут - это целенаправленно спроектированная индивидуальная образовательная программа, обеспечивающая студенту позицию субъекта учебно-профессиональной деятельности, способствующая формированию его самообразовательной деятельности на основе психолого-педагогического сопровождения его выбора в самореализации» [8, с. 63]. Как считает Р. Р. Сагитова, в качестве принципа обучения индивидуальная образовательная траектория служит теоретической базой рассмотрения каждого студента как личности на практическом уровне, несмотря на многочисленность и разнородность академических групп в вузах.

По утверждению А. А. Степаненко, А. В. Фещенко, одним из путей решения задачи индивидуализации обучения в современных условиях может стать изучение цифровых следов студентов, что, в свою очередь, «может помочь составить общее для всех субъектов учебного процесса видение моделей индивидуализации и найти системное решение для их реализации» [9, с. 58].

\section{Анализ модели индивидуальной траектории обучения студентов ИЯ на основе данных образовательной деятельности}

В рамках данного исследования нами была спроектирована модель индивидуальной траектории обучения студентов ИЯ, сочетающей в себе педагогический дизайн и анализ данных (Рис. 1). Модель учитывает основные условия обучения, такие как мотивация обучающегося и связанные с ним чувства самостоятельности, компетентности и целесообразности или полезности обучения.

Наибольшую популярность в современном образовании приобретает подход, объединяющий в себе персонализацию и кастомизацию учебных планов (основанную на взаимодействии с работодателями), анализ цифрового следа студентов, применение искусственного интеллекта для формирования программ. Развить эти направления в высшем образовании помогает цифровой инжиниринг [11]. На наш взгляд, суть модели индивидуальной траектории обучения студентов иностранному языку заключается в сочетании педагогического дизайна с анализом данных.

Как видно из модели, быстрый поиск информации о студенте в таких источниках, как социальные сети «BКонтакте» и LMS MOODLE, может быть предоставлен развитием методов сбора, анализа и интерпретации цифрового следа (пользовательских данных) студента. Исследование цифрового следа обучающегося, в свою очередь, позволяет смоделировать присущие ему физиологические, психологические и когнитивные особенности, которые могут быть использованы в процессе обучения для решения задач индивидуализации.

Цифровой профиль студента может быть дополнен информацией из электронного портфолио студента, которое хранится в ЕИС. Это могут быть данные о его или ее научно-исследовательской деятельности и академических достижениях.

Программные продукты Единой информационной среды учебного процесса (ЕИС) вуза (приводится пример Финуниверситета), относящиеся к институциональным системам, представляют важность для решения проблем, связанных с организацией и документальным обеспечением учебного процесса. В структурнологической модели данных ЕИС выделяют три связанных между собой программных модуля: «Студент», «Преподаватель», «Учебные дисциплины», причем формирование массива данных начинается с подсистемы «Абитуриент» [4]. 


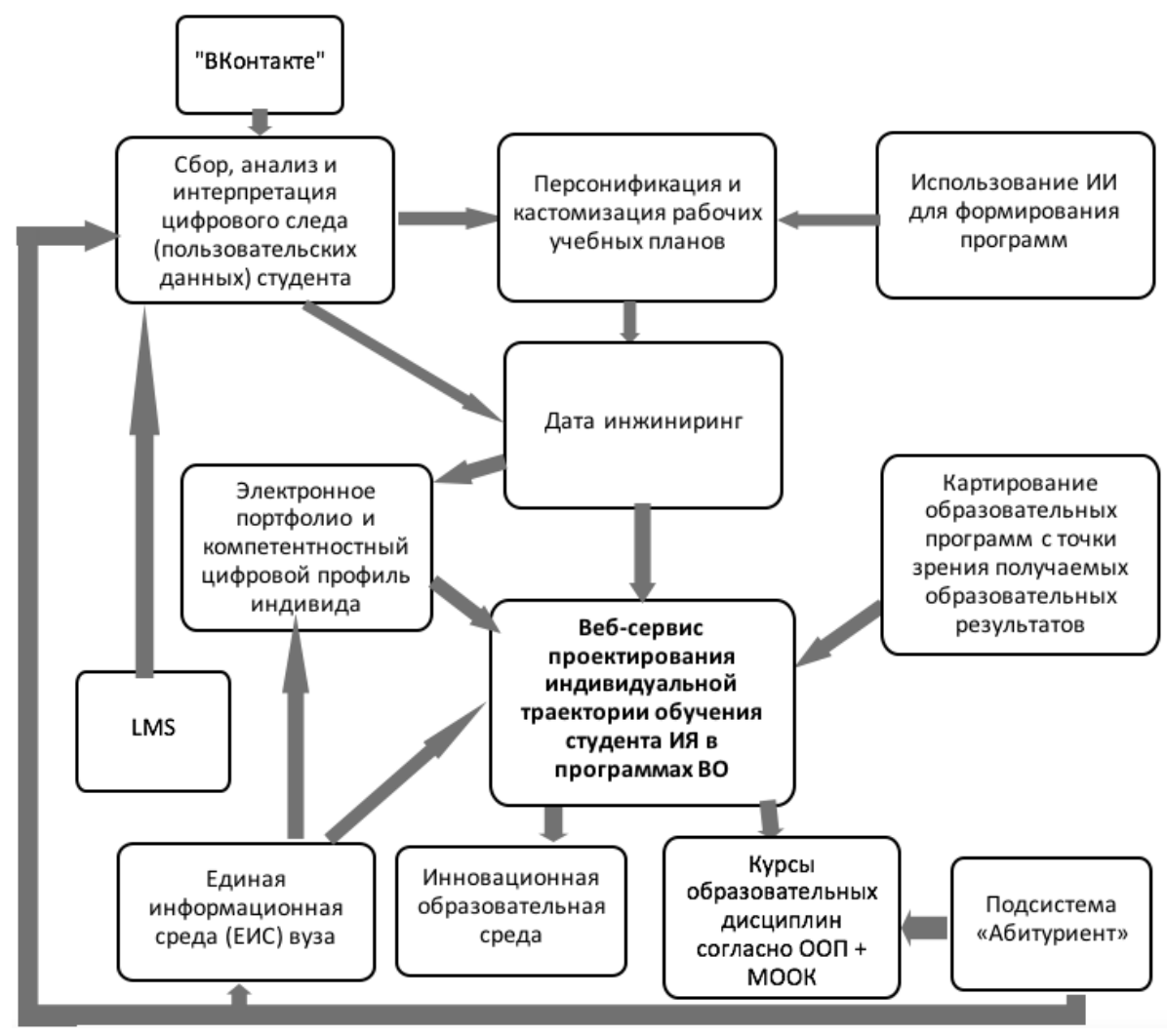

Рисунок 1. Модель индивидуальной траектории обучения студентов ИЯ Источник: составлено автором.

Так, например, анализ информации из подсистемы «Абитуриент» о медалях, победах в олимпиадах, результатах ЕГЭ по иностранному языку или модуля «Студент» может быть полезным для организации деятельности по индивидуализации обучения ИЯ, адаптации студентов к иноязычной образовательной среде. Для выявленных подсистемой «Абитуриент» студентов с высоким потенциалом («высокобалльники» и «олимпиадники») могут быть подготовлены определенные рабочие программы по ИЯ в дополнение к основной образовательной программе (ООП), которые позволят данной категории студентов максимальным образом реализовать свои способности, раскрыть талант и проявить интерес в таких образовательных траекториях, как:

- исследовательская;

- предпринимательская;

- профессиональная.

Важно отметить, что акцент специальной программы будет сделан на развитии «мягких», или, иначе говоря, гибких, навыков “soft skills” [9]. Согласно ФГОС высшего образования, у выпускников вузов должен быть сформирован ряд универсальных компетенций, таких как коммуникативная компетенция, умения критического мышления, а также soft skills. В иноязычной образовательной среде у студентов формируются «коммуникативные компетенции на основе смоделированных ситуаций общения, специально подобранной системы упражнений, отработки навыка публичного выступления, ведения диалога в профессиональной среде, участия в дискуссии и деловых переговорах, а также развиваются навыки критического мышления, связанные с необходимостью поиска, анализа и отбора нужной информации для решения повседневных и профессиональных задач. Развитие данных навыков осуществляется в процессе изучения устных тем, отбора материала для внеаудиторного чтения и написания эссе, участия в ролевой игре, проектной деятельности, применения кейстехнологии» [6, с. 67]. Помимо профессиональных знаний и навыков (hard skills), выпускник вуза должен обладать социально-психологическими навыками (soft skills) для успешности в выбранной профессии. Развитие гибких навыков “soft skills” неразрывно связано с формированием умений критического мышления и происходит через коллаборативное обучение, т.е. совместную работу преподавателей и обучающихся при решении проблемы или выполнении задания [2], работу в парах и малых группах, ролевую игру и проект.

Для решения задачи дополнительной помощи студентам со средним или невысоким баллом, выявленным подсистемой «Абитуриент», возможно привлечение внутриуниверситетских языковых курсов или внешних массовых открытых онлайн-курсов (МООК).

Система электронного обучения вуза (LMS Moodle) является еще одним программным компонентом ЕИС учебного процесса. LMS Moodle представляет собой онлайн-кампус и обладает широким набором возможностей для организации взаимодействия между преподавателем и студентами и полноценной реализации процесса обучения в электронной среде. Данный виртуальный кампус позволяет построить учебный процесс, посещать занятия, проводить текущий и промежуточный контроль, работать в электронных библиотеках 
и различных облачных технологиях. В системе LMS Moodle текущая аттестация по дисциплинам курса помогает выявить категории студентов, таких как «сильные» студенты, характеризующиеся высоким уровнем интеллекта, проявляющие личностную мотивацию, готовые выходить за рамки ООП для углубленного изучения дисциплины в МООК и требующие индивидуального управления траекторией обучения; «слабые»с большой вероятностью академической задолженности в конце семестра - для возможности дополнительной поддержки со стороны преподавателя [9].

В условиях смешанного обучения студентов в иноязычной образовательной среде проектирование индивидуальной образовательной траектории приобретает все большую значимость. Следует отметить, что большинство российских вузов активно применяют ИКТ и технологии электронного обучения в учебном процессе. Так, в частности, в Национальном исследовательском Томском политехническом университете (НИ ТПУ) на занятиях по иностранному языку «широко используется смешанное обучение на основе электронной обучающей среды LMS Moodle, обладающей дидактическим и функциональным потенциалом. Основными преимуществами данной технологии служат удобство размещения и использования учебно-методических материалов курса; гибкость в управлении учебным процессом, наличие различных средств коммуникации (электронная почта, обмен вложенными файлами с преподавателем, форум), чат, блоги, обмен личными сообщениями; возможность редактирования учетных записей и получения отчета о выполненных студентами заданиях; наличие различных инструментов для создания тестов и проведения тестирования в процессе обучения и контроля знаний» [3, с. 252].

Разнообразные модули (элементы курса), представленные в обучающей среде LMS Moodle, могут быть использованы преподавателем для создания электронного курса [3] - «комплекса учебно-методических материалов, обеспечивающих возможность обучаемому самостоятельно, с помощью компьютера, освоить содержание учебного курса с целью формирования и закрепления знаний, навыков, умений в определенной предметной области и в предусмотренном программой объеме» [1, с. 110].

Индивидуализация образовательного продукта по запросу конкретного потребителя в системе высшего образования называется кастомизацией обучения (от англ. to customize - настраивать, изменять что-то, делая более подходящим под нужды конкретного потребителя). Помимо возможности обучаться по индивидуальной траектории и достижения лучшего результата за меньшее время, кастомизированные учебные дисциплины по ИЯ позволяют повысить качество подготовки будущих выпускников за счет максимально расширенного содержания программ учебных дисциплин и адаптации под требования работодателей (например, мастерклассы специалистов-практиков, деловые игры, игровое проектирование, узкоспециализированные профессиональные кейсы), что повышает уровень конкурентоспособности выпускника на рынке труда [7]. Сегодня очевиден тот факт, что процессы в образовательной системе диктуют кастомизацию онлайн-обучения на основе интеллектуального анализа паттернов обучения или применения SUSU E-Learning 2.0 [Там же].

\section{Заключение}

Итак, данное исследование позволяет сделать следующие выводы. Значимость индивидуальной образовательной траектории в реализации личностного потенциала студента в процессе обучения определяется его способностью делать выбор, самостоятельно обучаться, принимать решения и готовностью к будущей профессиональной деятельности. Исходя из обзора научно-методических работ современных исследователей, мы можем определить индивидуальную образовательную траекторию как персонально разработанную дифференцированную образовательную программу на основе анализа цифрового следа студентов и применения технологий искусственного интеллекта с целью ориентации на студента и формирования его самообразовательной деятельности. В модели индивидуальной траектории обучения студентов ИЯ, представляющей собой сочетание педагогического дизайна с анализом данных, используются практические инструменты, которые помогают студентам быть более вовлеченными в обучение. Перспективы дальнейшего исследования проблемы мы видим в более подробном изучении модели индивидуальной образовательной траектории, включая применение технологий дополненной реальности, т.е. проецирование любой цифровой информации поверх экрана смартфона, планшета или смарт-очков с видеокамерой и соответствующим программным обеспечением.

\section{Список источников}

1. Азимов Э. Г., Щукин А. Н. Новый словарь методических терминов и понятий (теория и практика обучения языкам). М.: Икар, 2009. 448 с.

2. Бектасова Г. К. Коллаборативная среда как эффективная форма организации урока в условиях повышения качества образования и воспитания [Электронный ресурс] // Педагогическое мастерство: материалы VIII Междунар. науч. конф. (г. Москва, июнь 2016 г.). URL: https://moluch.ru/conf/ped/archive/191/10615/ (дата обращения: 29.11.2020).

3. Евсеева А. М. Реализация индивидуальной образовательной траектории для развития аудитивных умений студентов неязыкового вуза в условиях смешанного обучения // Филологические науки. Вопросы теории и практики. 2019. Т. 12. Вып. 2. С. 250-254. 
4. Единая информационная среда учебного процесса Финансового университета при Правительстве Российской Федерации (ЕИС) [Электронный ресурс]. URL: http://www.old.fa.ru/dep/ou/information_environment/ Pages/default.aspx (дата обращения: 29.11.2020).

5. Зеер Э. Ф., Сыманюк Э. Э. Индивидуальные образовательные траектории в системе непрерывного образования // Педагогическое образование в России. 2014. № 3. С. 74-82.

6. Иванова Г. Н. Развитие навыков и компетенций будущих специалистов в процессе изучения иностранного языка в вузе // Евразийский гуманитарный журнал. 2019. № S4 (2). С. 61-68.

7. Описание междисциплинарной научно-образовательной стратегической академической единицы (САЕ) ФГАОУ ВО «ЮУрГУ (НИУ)» «Умное образование» [Электронный ресурс] / Министерство образования и науки Российской Федерации. М., 2017. URL: https:/www.susu.ru/sites/default/files/book/sae_yuurgu_umnoe obrazovanie_rus_0.pdf (дата обращения: 15.02.2021).

8. Сагитова Р. Р. Индивидуальные образовательные маршруты как форма совершенствования самообразовательной компетенции студентов вуза в процессе обучения иностранному языку // Казанский педагогический журнал. 2016. № 2. Ч. 1. С. 62-65.

9. Степаненко А. А., Фещенко А. В. «Цифровой след» студента: поиск, анализ, интерпретация // Открытое и дистанционное образование. 2017. № 4 (68). С. 58-62. DOI: 10.17223/16095944/68/9.

10. Сысоев П. В. Обучение по индивидуальной траектории // Язык и культура. 2013. № 4 (24). С. 121-131.

11. Университет 20.35 представил программу своих мероприятий на конференции EdCrunch [Электронный pecypc]. URL: https://ntinews.ru/news/unti/universitet-20-35-predstavil-programmu-svoikh-meropriyatiy-nakonferentsii-edcrunch.html\# (дата обращения: 08.02.2021).

12. Хуторской А. В. Три типа личностно-ориентированного обучения. К ученику, от него или вместе с ним? [Электронный ресурc]. URL: http://khutorskoy.ru/be/2018/0221/ (дата обращения: 01.02.2021).

13. Ваo W. COVID-19 and online teaching in higher education: A case study of Peking University [Электронный pecypc]. URL: https://onlinelibrary.wiley.com/doi/full/10.1002/hbe2.191 (дата обращения: 08.02.2021).

14. COVID-19 Education: From disruption to recovery. UNESCO (2020, March 13) [Электронный pecypc]. URL: https://en. unesco.org/covid19/educationresponse (дата обращения: 08.02.2021).

15. Mkrttchian V. Avatar manager and student reflective conversations as the base for describing meta-communication model / ed. by G. Kurubacak, T. Vokan Yuzer, U. Demiray // Meta-communication for reflective online conversations: Models for distance education. Hershey, PA: IGI Global, 2012. P. 340-351. DOI: 10.4018/978-1-61350-071-2.ch005.

16. Mulenga E. M., Marbán J. M. Prospective Teachers' Online Learning Mathematics Activities in the Age of COVID-19: A Cluster Analysis Approach [Электронный ресурс] // EURASIA Journal of Mathematics, Science and Technology Education. 2020. Vol. 16. Iss. 9. URL: https://www.ejmste.com/article/prospective-teachers-online-learningmathematics-activities-in-the-age-of-covid-19-a-cluster-8345 (дата обращения: 08.02.2021).

17. Picciano A. G. Theories and frameworks for online education: Seeking an integrated model [Электронный pecypc] // Online Learning Journal. 2017. Vol. 21. № 3. URL: https://olj.onlinelearningconsortium.org/index.php/ olj/article/view/1225 (дата обращения: 08.02.2021).

18. 290 million students out of school due to COVID-19 [Электронный pecypc]. URL: https://en.unesco.org/news/ 290-million-students-out-school-due-covid-19-unesco-releases-first-global-numbers-and-mobilizes (дата обращения: 08.02.2021).

\section{Информация об авторах | Author information}

RU Васьбиева Динара Гиниятулловна ${ }^{1}$, к. экон. н., доц.

${ }^{1}$ Финансовый университет при Правительстве Российской Федерации, г. Москва

EN Vasbieva Dinara Giniyatullovna ${ }^{1}, \mathrm{PhD}$

${ }^{1}$ Financial University under the Government of the Russian Federation, Moscow

${ }^{1}$ dinara-va@list.ru

\section{Информация о статье | About this article}

Дата поступления рукописи (received): 18.01.2021; опубликовано (published): 09.04.2021.

Ключевые слова (keywords): индивидуальная траектория; цифровой след; образовательная траектория; иноязычная образовательная среда; цифровой профиль; individual trajectory; digital footprin; educational trajectory; foreign language educational environment; digital profile. 